\title{
PERSEPSI MASYARAKAT TERHADAP AKTIVITAS PENAMBANGAN GALIAN C DI BUKIT PENIRAMAN DESA PENIRAMAN KECAMATAN SUNGAI PINYUH KABUPATEN MEMPAWAH
}

\author{
(Community Perception of Mining Activities C Excavation in Bukit Peniraman, The Village \\ Peniraman, Sungai Pinyuh District, Mempawah Regency)
}

\author{
Mulyani Puspita Sari, Sudirman Muin, M. Dirhamsyah \\ Fakultas Kehutanan Universitas Tanjungpura, Jalan Imam Bonjol Pontianak, 78124 \\ Email :mulyanipuspitasari30@gmail.com
}

\begin{abstract}
Perception is a process that involves the entry of messages or information into the human brain. Through perception, human could connect constantly with their environment. Peniraman Village has natural resource potential in the form of type C trenching (Stone and Soil) which gives rise to various perceptions from the community. This study aims to determine the community perception towards type $C$ trenching activities in Peniraman Hill and find out the relationship between the level of education, income and cosmopolitan factors. This study uses a survey method with observation, interviews and questionnaires containing a number of questions asked to the respondents, The data is collected using purposive random sampling. Analysis of the data is using descriptive analysis of the chi square test and inferential analysis using nonparametric statistical tests of the Kendall Tau correlation. The respondents in this study is 68 people. The results of this study indicate that people's perceptions tend to be positive, the level of income level is low, the level of cosmopolitan is moderate. There is a positive and significant correlation between education level and perception, and there is no significant correlation and there is no relation between the level of income and cosmopolitan levels with the community perception.
\end{abstract}

Keywords: Community Perception, Mining, Peniraman Village

\section{PENDAHULUAN}

Persepsi adalah proses penilaian seseorang/sekelompok orang terhadap objek, peristiwa, atau stimulus dengan melibatkan pengalaman-pengalaman yang berkaitan dengan objek tersebut (Ni'am dan Mussadun, 2014). Menurut Slameto (2013). Persepsi adalah proses yang menyangkut masuknya pesan atau informasi ke dalam otak manusia. Melalui persepsi manusia terus-menerus mengadakan hubungan dengan lingkungannya. Menurut Leavitt 2016 Persepsi adalah yaitu bagaimana seseorang memandang atau mengartikan sesuatu.

Sumber daya alam merupakan unsurunsur lingkungan alam, baik fisik maupun hayati yang diperlukan manusia dalam memenuhi kebutuhannya guna meningkatkan kesejahteraan hidup (Jamaril et al, 2016). Sumber daya alam bisa terdapat dimana saja seperti di dalam tanah, air, permukaan tanah, udara, dan lain sebagainya.

Bukit Peniraman tersebut sebelumnya merupakan kawasan berhutan yang dimanfaatkan oleh masyarakat Desa peniraman untuk 
memenuhi kebutuhan ekonomi dan budayanya, baik yang bermanfaat secara langsung ataupun tidak langsung dari hasil hutan tersebut. Kegiatan penambangan galian $\mathrm{C}$ tersebut memberikan dampak negative terhadap lingkungan yaitu menyebabkan kerusakan hutan, namun juga memberikan dampak positif dibidang ekonomi, seperti memberikaan kesempatan lapangan pekerjaan dan memjadi sumber pendapatan bagi masyarakat (Rahmawati, 2010). Namun karna ketidak puasan manusia dan kurangnya kesadaran masyarakat dalam menjaga lingkungan yang menyebabkan perubahan fungsi lahan menjadi pengundulan hutan yang dilakukan penggerusan secara terus-menerus. Desa Peniraman yang teridiri 5 (lima) dusun adalah salah satu dari desa yang berada di wilayah Kecamatan Sungai Pinyuh, Kabupaten Mempawah. Desa Peniraman memiliki potensi alam yang besar khususnya sumber daya alam Galian $\mathrm{C}$ (batu dan tanah). Aktivitas penambangan Galian C di Bukit Peniraman Desa Peniraman sudah berlangsung sejak tahun 1960 sampai sekarang.

Pada awalnya kegiatan penambangan Galian C (batu dan tanah) dilakukan oleh masyarakat setempat yang bertujuan untuk pembanguan infrastruktur bangunan pribadi (pembangunan rumah masyarakat) atau kebutuhan pembangunan infrastruktur di Desa Peniraman. Seiring berkembangannya pembanguan di daerah,khususnya di Kota Pontianak, sehingga aktivitas kegiatan penambangan galian $\mathrm{C}$ (batu dan tanah) sudah dilakukan oleh perusahaan swasta dengan menggunakan peralatan yang bukan bersifat tradisional seperti pacul, skop, linggis dan lain-lain, akan tetapi perusahaan dalam melakukan penambangan sudah menggunakan peralatan-peralatan besar seperti bolldozer, exsavator, looder dan alat angkut mobil truk, Seiring dengan perkembangan tekhnologi dan informasi yang begitu pesat yang sejalan dengan meningkatnya kebutuhan hidup yang terus menerus bertambah tanpa batas, dimana kebutuhan komsumsi harus diseimbangkan dengan hasil produksi, begitupun halnya dengan lingkungan dimana pemanfaatan lahan harus disertai dengan pelestarian lingkungan. Saat ini sekarang terdapat 5 (lima) perusahaan yang masih aktif beroperasi dalam kegiatan penambangan Galian C di Bukit Peniraman Desa Peniraman.

Adanya aktivitas penambangan Galian C di Bukit Peniraman, Desa Peniraman, masyarakat cukup merasakan manfaat adanya kegiatan tersebut, antara lain masyarakat mendapatkan lapangan pekerjaan sehingga dapat menambah pengahasilan masyarakat. Seiring berjalannya waktu, dimana kegiatan penambangan galian $\mathrm{C}$ (batu dan tanah) dilakukan secara besar-besaran sehingga mulai terjadi kerusakaan dan pencermaran lingkungan khususnya di Desa Peniraman.

Menurut beberapa masyarakat setempat, adanya perusahaan tambang di daerah tempat tinggal mereka turut membantu dan baik, karena dapat menambah lapangan pekerjaan dan 
meningkatkan pendapatan masyarakat. Akan tetapi, pada kenyataannya pendapatan yang diterima masyarakat yang bekerja sebagai penambang batu dan tanah sangat kecil dan tidak sesuai dengan tenaga yang telah mereka keluarkan. Seperti upah penambang batu dalam 1 paketnya hanya Rp20.000 sedangkan tanah Rp30.000 per paket, sementara menambang batu lebih banyak mengeluarkan tenaga dan lebih beresiko dibandingkan dengan menambang tanah.

Menurut Dela (2015) tingkat pendidikan, pekerjaan dan umur mempengaruhi tingkat persepsi dan tingkat pengetahuan masyarakat terhadap pentingnya fungsi ruang terbuka hijau di Kota Pontianak. Semakin tinggi tingkat pendidikan maka tingkat persepsi masyarakat tinggi dan tinggi tingkatan umur serta tingkat pekerjaan maka tingkat persepsi masyarakat juga tinggi. Guna mengetahui persepsi masyarakat terhadap aktivitas penambangan galian $\mathrm{C}$, maka perlu dilakukan penelitian mengenai persepsi masyarakat terhadap aktivitas penambangan galian C. Penelitian ini bertujuan untuk mengetahui persepsi masyarakat terhadap aktivitas penambangan galian $\mathrm{C}$ dan mengetahui hubungan faktor tingkat pendidikan, pendapatan, dan kosmopolitan dengan persepsi masyarakat Desa Peniraman, Kecamatan Sungai Pinyuh, Kabupaten Mempawah terhadap aktivitas penambangan galian $\mathrm{C}$.

\section{METODE PENELITIAN}

Penelitian ini dilaksanakan di Desa Peniraman Kecamatan Sungai Pinyuh Kabupaten Mempawah. Pengumpulan data dilakukan dalam waktu 1 bulan di lapangan, dimulai tanggal 1-30 Juni 2019. Penelitian ini menggunakan metode survey yang bersifat deskriptif dan inferensial dengan teknik observasi, wawancara dan alat bantu kuesioner berupa formulir daftar pertanyaan yang diajukan kepada sejumlah responden. Metode pengambilan sampel penelitian dengan menggunakan metode Purposive Random Sampling. Penentukan besarnya ukuran sampel dalam penelitian ini akan dihitung dengan rumus Slovin (Khadapi, 2015) sebagai berikut:

$n i=\frac{N i}{1+\sum N i . e^{2}}$

Keterangan :

ni = Jumlah sampel ke $\mathrm{i}$

$\mathrm{Ni} \quad=$ Jumlah populasi ke $\mathrm{i}$

$\sum \mathrm{Ni}=$ Total Pupulasi Ni

$\mathrm{e} \quad=$ Tingkat error $(12 \%)$. Tingkat Kepercayaan $88 \%$.

Diketahui jumlah sampel $1759 \mathrm{KK}$ dari 5 Dusun yaitu Dusun Teratai, 372 KK, Dusun Babussalam 367 KK, Dusun Sungai Dayak 335,Dusun Peniraman Dalam 300 KK, Dusun Danau Gambir 385 KK. Persen Kesalahan yang digunakan dalam penelitian ini adalah 12\%. Dapat disimpulkan bahwa sampel yang digunakan dalam penelitian ini sebanyak $68 \mathrm{KK}$.

Kriteria masyarakat yang akan dijadikan responden secara purposive random sampling yaitu: (a). Kepala Keluarga (b). Sehat Jasmani dan Rohani (c). Umur minimal 18 tahun (d). Berdomisili minimal 5 tahun. Berdasarkan perhitungan menggunakan rumus slovin didapat total responden 68 responden karena sudah dapat mewakili 
dari populasi dan untuk menghemat biaya serta waktu penelitian.

Data yang dikumpulkan meliputi: (1) data primer yaitu data mengenai persepsi masyarakat terhadap aktivitas penambangan galian $\mathrm{C}$ di Bukit Peniraman Desa Peniraman, yang akan dihubungkan dengan tingkat pendidikan, pendapatan dan tingkat kosmopolitan, (2) data sekunder yaitu data penunjang yang berhubungan dengan keadaan lokasi penelitian, diperoleh dari instansi terkait yang menunjang hasil penelitian. Data ini meliputi peta lokasi, catatan, rekaman dan keadaan umum lokasi penelitian. Data tersebut ditabulasikan dan kemudian dianalisis menggunakan Chi Square (Sugiyono, 2017) dengan rumus sebagai berikut:

$X^{2}=\sum_{i=1}^{k} \frac{(f 0-f h)^{2}}{f n}$

Keterangan :

$X^{2}$ : Chi Kuadrat

$\mathrm{F}_{0} \quad$ : Frekuensi observasi

$\mathrm{F}_{\mathrm{h}}$ : Frekuensi harrapan

untuk mengetahui hubungan variabel terikat dan variabel bebas dilakukan menggunakan Uji Statistik Non Parametrik Uji Korelasi Kendall Tau dengan rumus seperti berikut (Priyatno, 2010) :

$$
\tau=\frac{\sum A-\sum B}{\frac{N(N-1)}{2}}
$$

Keterangan :

$\tau=$ Koefesien Korelasi Kendall Tau yang besarnya $(-1<0<1)$

A = Jumlah rangkaian atas

$\mathrm{B}=$ Jumlah rangkaian bawah

$\mathrm{N}$ = Jumlah gagasan sampel

Persepsi masyarakat di ukur dengan memberikan skor menggunakan Skala Likert (skor 5-1) yakni tingkat persetujuan responden terhadap pernyataan yang dikemukan si peneliti yang berhubungan tingkat pendidika, Pendapatan, kosmopolitan dengan persepsi masyarakat terhadap aktivitas penambangan galian $\mathrm{C}$ di Bukit Peniraman, Desa Peniraman yang meliputi jawaban ; (a) sangat setuju, skor 5, (b) setuju, skor 4, (c) kurang setuju, skor 3, (d) tidak setuju, skor 2, dan (e), sangat tidak setuju, skor 1, dan selanjutnya tingkat persepsi masyarakat tersebut dikelompokkan menjadi 3 katagori.

Untuk merubah tingkat persepsi masyarakat terhadap aktivitas penambangan galian $\mathrm{C}$ di Bukit Peniraman Desa Peniraman dari 5 (lima) kategori menjadi 3 (tiga) kategori dilakukan dengan menggunakan persamaan persamaan Convidence Interval (Selang Kepercayaan) menurut Hasril Hitam (1980) yang digunakan Muin, S (2018) berikut :

$\mathrm{CI}=\mathrm{X} \pm \mathrm{t} . \mathrm{Sx}$

Keterangan :

$\mathrm{CI}=$ Convidence Interval (Selang Kepercayaan)

$\mathrm{X}=$ Nilai Tengah (rata-rata $\mathrm{X}$ )

$\mathrm{t} \quad=\mathrm{t}$ tabel $(88 \%)$.

Sx $=$ Standar error

$S x=\sqrt{1-f\left(\frac{V r}{n}\right)}$

Dimana :

f : Intensitas sampling $(0,04)$.

$\mathrm{Vr} \quad$ : Varians $\left(\mathrm{Sd}^{2}\right)$

n : Jumlah Sample.

Dengan ketentuan kategori sebagai berikut :

Kategori Tinggi, jika $\mathrm{CI}=\geq \mathrm{X}+\mathrm{t}$. Sx

Kategori Sedang, jika CI $=\mathrm{X}-\mathrm{t}$. Sx s/d $<\mathrm{X}+\mathrm{t}, \mathrm{Sx}$ 
Kategori Rendah, jika CI $=<\mathrm{X}-\mathrm{t}$.Sx Untuk menganalisis data secara infrensial (Korelasi Kendall Tau), tingkat pendapatan dengan kategori Tinggi diberi skor 3, tingkat pendapatan dengan kategori Sedang diberi skor 2, dan tingkat pendapatan dengan kategori Rendah diberi skor 1.

\section{HASIL DAN PEMBAHASAN}

Frekuensi Responden Berdasarkan Tingkat Variabel

Frekuensi Tingkat Persepsi

Tabel 1. Frekuensi Responden Berdasarkan Tingkat Persepsi (Frequency of Respondents Based On Perception Level)

\begin{tabular}{cccc}
\hline No & Persepsi & Frekuensi & Persentase (\%) \\
\hline 1 & Positif & 35 & 51,47 \\
2 & Netral & 8 & 11,76 \\
3 & Negatif & 25 & 36,76 \\
\hline & & 68 & 100,00 \\
\hline
\end{tabular}

Sumber :Hasil Analisi Data Primer 2019

Tabel 1 menunjukan bahwa 35 responden $(51,47 \%)$ mempunyai persepsi positif terhadap aktivitas penambangan galian C di Desa Peniraman Kecamatan Sungai Pinyuh Kabupaten Mempawah, 8 responden $(11,76 \%)$ mempunyai persepsi netral terhadap aktivitas penambangan galian C di Bukit Peniraman Desa Peniraman dan 25 responden $(36,76 \%)$ yang mempunyai persepsi negatif terhadap aktivitas penambangan galian $\mathrm{C}$ di Desa Peniraman. Masyarakat yang memiliki persepsi yang positif yaitu mereka yang menganggap aktivitas penambangan galian $\mathrm{C}$ tersebut dapat menambah lapangan pekerjaan dan menambah peningkatan ekonomi untuk kebutuhan hidupya sehari-hari.
Menurut penilaian responden, usaha tambang galian $\mathrm{C}$ dapat mengurangi jumlah pengangguran di Desa Peniraman, Kecamatan Sungai Pinyuh, karena adanya aktivitas penambangan galian $\mathrm{C}$ dapat menciptakan lapangan kerja bagi masyarakat setempat, terutama masyarakat yang berpendidikan rendah. Umumnya jenis pekerjaan yang dilakukan adalah pekerjaan yang hanya memerlukan kekuatan fisik. Dengan bekerja sebagai buruh di perusahaan penambangan galian $\mathrm{C}$ dapat meningkatkan perekonomian rumah tangga keluarga. Namun demikian, tidak semua masyarakat yang berpendidikan rendah bekerja di penambangan Galian C, sebagian besar masyarakat bekerja sebagai petani dan swasta. 
Frekuensi Tingkat Pendidikan

Tabel 2. Frekuensi Responden Berdasarkan Tingkat Pendidikan ((Frequency Of Respondents BasedOn Education)

\begin{tabular}{ccccc}
\hline No & $\begin{array}{c}\text { Kategori Tingkat } \\
\text { Pendidikan }\end{array}$ & $\begin{array}{c}\text { Jumlah } \\
(\text { KK })\end{array}$ & Persentase & Keterangan \\
\hline 1 & Tidak Sekolah-SD & 14 & 20,59 & Rendah \\
2 & SLTP & 26 & 38,24 & Sedang \\
3 & SLTA-Perguruan Tinggi & 28 & 41,18 & Tinggi \\
\hline & Total & 68 & 100,00 & \\
\hline
\end{tabular}

Sumber :Hasil Analisi Data Primer 2019

Berdasarkan hasil olahan data primer terhadap pengamatan dilapangan diperoleh frekuensi yang bervariasi dengan 68 responden yang menunjukan bahwa 14 responden $(20,59 \%)$ mempunyai tingkat pendidikan yang rendah (SD), sedangkan 26 responden $(38,24 \%)$ mempunyai tingkat pendidikan sedang (SLTP), dan sebanyak 28 responden $(41,18 \%)$ mempunyai tingkat pendidikan tinggi terbanyak yaitu (SMAPerguruan Tinggi). Hal ini menunjukan bahwa pendidikan masyarakat di Desa Peniraman berada pada kategori tinggi yaitu SLTA-Perguruan Tinggi.

Masyarakat yang berpendidikan tinggi maupun rendah berpersepsi positif terhadap aktivitas penambangan galian $\mathrm{C}$ di Bukit Peniraman. Masyarakat yang berpersepsi positif dikarenakan

Frekuensi Tingkat Pendapatan

Tabel 3. Frekuensi Berdasarkan Tingkat Pendapatan (Frequency Of Respondents Based on income level )

\begin{tabular}{ccccc} 
No & $\begin{array}{c}\text { Kategori } \\
\text { Pendapatan }\end{array}$ & Pendapatan(Rp/Bulan) & Frekuensi & Persentase $(\%)$ \\
\hline 1 & Tinggi & $\geq 1.873 .460$ & 19 & \\
2 & Sedang & $1.624 .481 \mathrm{~s} / \mathrm{d} 1.873 .460$ & 12 & 27,94 \\
3 & Rendah & $<1.624 .481$ & 37 & 17,65 \\
\hline & Jumlah & 68 & 100,00 \\
\hline
\end{tabular}

Sumber :Hasil Analisi Data Primer 2019

Berdasarkan sampel penelitian terhadap 68 responden, terdapat 19 responden $(27,94 \%)$ tergolong dalam kelompok pendapatan tinggi yaitu lebih masyarakat berpandangan bahwa adanya aktivitas penambangan galian $\mathrm{C}$ di Bukit Peniraman lebih banyak memberikan dampak positif bagi kehidupan masyarakat Desa Peniraman, antara lain memberikan lapangan pekerjaan, dan adanya usaha baru seperti warung.Selain peningkatan kesejateraan masyarakat, keberadaan perusahaan yang melakukan kegiatan penambang galian $\mathrm{C}$ juga memberikan dampak yang positif dalam pembangunan infrastruktur desa, diantaranya adalah adanya biaya administrasi yang dibayarkan oleh pengusaha Galian C kepada Desa Peniraman yang digunakan untuk pembangunan insfrastruktur desa seperti pembangunan tempat ibadah dan sebagainya. dari Rp 1.873.460 per bulan, sebanyak 12 responden $(17,65 \%)$ tergolong dalam kelompok pendapatan sedang antara $\mathrm{Rp}$ 1.624.481 s/d 1.873.460 per bulan, dan 
sebanyak 37 responden $(54,41 \%)$ termasuk dalam pendapatan rendah yaitu di bawah Rp 1.624.481 per bulan. Dapat disimpulkan bahwa, dari 68 responden penelitian diperoleh tingkat pendapatan responden terbanyak adalah pada tingkat pendapatan kurang dari 1.624.481 per bulan yaitu sebanyak 37 responden $(54,41 \%)$ di Desa Peniraman yang memiliki pendapatan tergolong rendah. Sebagian besar masyarakat Desa Peniraman bekerja sebagai petani dan buruh tani, bekerja di bidang jasa lainnya seperti sebagi buruh penambangan galian $C$ di Bukit Peniraman. Hal ini menunjukkan bahwa pendapatan masyarakat Desa Peniraman sebagian besar diperoleh dari hasil tani atau sebagai buruh tani, dan sebagian kecil dari pekerjaan jasa lainnya antara lain sebagai buruh penambangan galian $\mathrm{C}$ di Bukit Peniraman. Artinya, adanya aktivitas penambangan galian $\mathrm{C}$ di Bukit Peniraman tidak berpengaruh terhadap jenis pekerjaan yang dijalani maupun tingkat pendapatan sebagian besar masyarakat Desa Peniraman. Hal ini tidak sejalan dengan hasil penelitian Alpian (2009), menyatakan bahwa masyarakat yang mempunyai pendapatan rendah cenderung mempunyai tingkat persepsi negatif.

\section{Frekuensi Tingkat Kosmopolitan}

Tabel 4. Frekuensi Responden Berdasarkan Tingkat Kosmopolitan (Frequency of Respondents Based on Cosmopolitan)

\begin{tabular}{cccc}
\hline No & Kosmopolitan & Frekuensi & Persentase (\%) \\
\hline 1 & Tinggi & 17 & 25,00 \\
2 & Sedang & 31 & 45,59 \\
3 & Rendah & 20 & 29,41 \\
\hline & Jumlah & 68 & 100,00 \\
\hline
\end{tabular}

Sumber :Hasil Analisi Data Primer 2019

Berdasarkan hasil penelitian dari 68 responden yang terdapat di Desa Peniraman menunjukan bahwa 17 responden $(25 \%)$ mempunyai tingkat kosmopolitan tinggi, 31 responden $(45,59 \%) \quad$ mempunyai tingkat kosmopolitan sedang dan 20 responden $(29,41 \%) \quad$ mempunyai tingkat kosmopolitan yang rendah terhadap aktivitas penambangan galian $\mathrm{C}$ di Bukit Peniraman.

Berdasarkan pengamatan di lapangan, tingkat kosmopolitan yang sedang tersebut disebabkan karena sebagian besar masyarakat belum mau atau kurang memiliki keterbukaan dalam menerima informasi-informasi yang ada, hal ini dikarenakan masyarakat hanya berpergian untuk kepentingan yang mendesak saja seperti membeli barangbarang kebutuhan toko, berkunjung kerumah keluarga, membeli kebutuhan rumah tangga, menjenguk keluarga yang sedang sakit, serta menghadiri undangan pernikahan keluarganya, sehingga masyarakat hanya bepergian dalam waktu yang singkat. Selain itu, sosialisasi ataupun penyuluhan terkait adanya aktivitas penambangan galian $\mathrm{C}$ dari dinas terkait pun belum secara merata dilakukan. 
Dalam penelitiannya Asang (2016), mengemukakan Perbedaan tingkat kosmopolitan terjadi karena adanya perbedaan sumber informasi yang diterima masyarakat. Kelompok masyarakat yang memiliki kosmopolitan tinggi dan sedang ialah masyarakat yang memiliki interaksi dengan dunia luar lebih banyak, baik interaksi dua arah maupun satu arah sehingga mempunyai kawasan berpikir yang luas sehingga membuat mereka mampu menerima halhal baru yang bersifat positif, sedangkan masyarakat dengan tingkat kosmopolitan rendah ialah masyarakat yang minim dalam berinteraksi dan menerima informasi dari luar sehingga memiliki wawasan yang sempit dan akan sulit untuk menerima hal-hal yang baru di lingkungannya.

\section{Analisis Deskriptif}

Persepsi masyarakat terhadap aktivitas penambangan galian $\mathrm{C}$ di Bukit Peniraman Desa Peniraman dianalisa dengan analisis deskriptif dengan uji statistik deskriptif menggunakan tabulasi frekuensi. Berdasarkan olahan data primer hasil pengamatan langsung dilapangan dengan perolehan kategori frekuensi persepsi responden terhadap aktivitas penambangan galian $\mathrm{C}$ yaitu terdapat data positif sebanyak 35 responden $(51,47 \%)$, netral sebanyak 8 responden $(11,47 \%)$, dan negatif sebanyak 25 responden (36,76\%). Disajikan Pada Tabel 5.

\section{Tabel 5. Uji Statistik Deskriptif Chi Square}

\begin{tabular}{ccccccc} 
No & $\begin{array}{c}\text { Alternatif } \\
\text { Pilihan }\end{array}$ & Fo & Fh & Fo-Fh & $(\text { Fo-Fh })^{2}$ & $\frac{(F o-F h)^{2}}{F h}$ \\
\hline 1 & Positif & 35 & 22,67 & 12,33 & 152,03 & 6,71 \\
2 & Netral & 8 & 22,67 & $-14,67$ & 215,21 & 9,49 \\
3 & Negatif & 25 & 22,67 & 2,33 & 5,43 & 0,24 \\
\hline & Jumlah & 68 & 68 & $-0,01$ & 372,67 & 16,44 \\
\hline
\end{tabular}

Sumber :Hasil Analisi Data Primer 2019

Hasil uji statistik deskiptif (uji Chi Square) diperoleh nilai Chi Square (r) hitung pada taraf kepercayaan $95 \%$ sebesar 16,44. Nilai Chi Square hitung 16,44 tersebut lebih besar dari uji nilai Chi Square tabel sebesar 5,59. Dengan demikian, dapat disimpulkan bahwa terdapat perbedaan signifikan frekuensi persepsi masyarakat terhadap aktivitas penambangan galian $\mathrm{C}$ di Bukit Peniraman, Desa Peniraman, Kecamatan Sungai Pinyuh, Kabupaten Mempawah. Hal ini berarti secara keseluruhan bahwa, persepsi masyarakat terhadap aktivitas penambangan galian $\mathrm{C}$ di
Bukit Peniraman, Desa Peniraman cenderung positif, sebagaimana ditunjukan hasil olahan data primer pada Tabel 15 dimana $51,47 \%$ responden cenderung berpersepsi positif dan $36,76 \%$ cenderung berpersepsi negatif terhadap aktivitas penambangan galian C di Bukit Peniraman, Desa Peniraman, Kecamatan Sungai Pinyuh, Kabupaten Mempawah. Hasil pengamatan dilapangan diperoleh informasi bahwa responden yang mempunyai persepsi positif terhadap aktivitas penambangan galian C di Bukit Peniraman karena terdapat berbagai dampak positif yang dirasakan 
oleh sebagian besar masyarakat, namun masih terdapat pula dampak negatif yang dirasakan oleh beberapa masyarakat. Menurut Matteson (2011) adalah proses kognitif dimana individu menyeleksi, mengorganisasi, dan memberi arti terhadap stimuli lingkungan. Setiap individu memiliki persepsi yang berbeda-beda, meskipun melihat stimuli yang sama.

Berdasarkan hasil data primer diperoleh bahwa tingkat persepsi masyarakat terhadap aktivitas penambangan galian $\mathrm{C}$ dipengaruhi oleh tingkat pendidikan dan kosmopolitan. Menurut Nurkaromah (2017) Pendidikan itu sendiri dipengaruhi oleh faktor pendidikan formal, dimana diharapkan pendidikan yang tinggi maka orang tersebut akan semakin luas pengetahuannya. Akan tetapi, perlu ditekankan bukan berarti seseorang yang berpendidikan rendah mutlak berpengetahuan rendah, hal ini mengingat bahwa peningkatan pengetahuan tidak mutlak diperoleh pendidikan formal saja, akan tetapi dapat diperoleh dari pendidikan non formal dan keterbukaan masyarakat dalam mencari dan menerima informasi baru. Responden dengan tingkat pendidikan tinggi yang memiliki persepsi positif yaitu masyarakat yang mempunyai wawasan yang luas, mempunyai pola pikir yang baik dan mau menerima berbagai informasi darurat secara khusus mengenai aktivitas penambangan galian $\mathrm{C}$.

Responden dengan tingkat pendidikan sedang memiliki persepsi yang netral terhadap aktivitas penambangan galian $\mathrm{C}$ ini dinyatakan pendidikan seseorang berpengaruh terhadap pandangan seseorang, jika pendidikan mereka rendah maupun sedang bukan berarti pemahaman mereka kurang akan tetapi masayarakat menilai berdasarkan apa yang mereka lihat, berdasarkan pengetahuan dan berdasarkan pengalaman yang mereka miliki.

Menurut Surati (2014) perilaku merupakan perbuatan dan perkataan seseorang yang sifatnya dapat diamati, digambarkan dan dicatat oleh orang lain ataupun orang yang melakukannya. Responden yang memiliki pendidikan rendah memiliki persepsi yang negatif terhadap aktivitas terhadap penambangan galian $\mathrm{C}$, menyatakan pendidikan seseorang berpengaruh pada pandangan seseorang, jika pendidikan mereka rendah maupun sedang bukan berarti pemahaman mereka kurang akan tetapi masyarakat menilai berdasarkan apa yang mereka lihat, berdasarkan pengetahuan dan berdasarkan pengalaman yang mereka miliki.

Tingkat pendapatan masyarakat terhadap aktivitas penambangan galian $\mathrm{C}$ di Desa Peniraman 54,41\% cenderung rendah dan persepsi cenderung negatif, hal ini dikarenakan gaji yang diperoleh dari hasil pekerjaan selama satu bulan, disebabkan pekerjaan masyarakat yang bervariasi sehingga mengakibatkan pendapatan masyarakat menjadi rendah, tetapi masih ada masyarakat yang tetap bekerja sebagai penambang untuk kebutuhannya sehari-hari karena sebagai penunjang kehidupannya.

Sedangkan dengan responden yang berpendapatan yang tinggi memiliki persepsi positif terhadap aktivitas penambangan galian $\mathrm{C}$ karena masyarakat merasakan banyak dampak yang positif dari aktivititas penambangan galian $\mathrm{C}$ yang salah 
satunya menambah penghasilan dan peningkatan ekonominya.

\section{Analisis Inferensial}

Variabel terikat dalam penelitian ini adalah persepsi masyarakat terhadap aktivitas penambangan galian $\mathrm{C}$ di Bukit Peniraman, sedangkan variabel bebas tingkat pendidikan, tingkat pendapatan, tingkat kosmopolitan. Untuk melihat hubungan variabel terikat dan variabel bebas dalam penelitian ini dianalisis dengan analisis inferensial dengan menggunakan uji statistik uji Kendall Tau. Hasil uji korelasi pearson variabel terikat dengan variabel bebas dapat dilihat Pada Tabel 6 .

Tabel 6. Hasil Uji Statistik Korelasi Kendall Tau Hubungan Variabel Terikat Dengan Variabel Bebas.

\begin{tabular}{cccccc}
\hline No & Variabel & $\mathrm{N}$ & $\begin{array}{c}\text { Correlation } \\
\text { Coefficient }\end{array}$ & Sig.(2-tailed) & Keteranga \\
\cline { 3 - 6 } 1 & Pendidikan & 68 & 0.217 & 0.029 & $\begin{array}{c}\text { Berhubungan Positif } \\
\text { Signifikan } \\
\text { Berhubungan Negatif } \\
\text { Tidak Signifikan }\end{array}$ \\
2 & Pendapatan & 68 & -0.043 & 0.633 & $\begin{array}{c}\text { Berhubungan Negatif } \\
\text { Tidak Signifikan }\end{array}$ \\
\hline
\end{tabular}

Sumber :Hasil Analisi Data Primer 2019
1. Hubungan
Persepsi
Masyarakat

Terhadap Aktivitas Penambangan Galian

C Dengan Tingkat Pendidikan

Hasil uji statistik (Uji Kendall Tau) sebagaiman diuraikan pada tabel 6 diketahui nilai Sig.(2-tailed) sebesar 0,029 dan nilai Correlation Coefficient positif 0,217. Nilai Sig $0,029<0,050$, sehingga disimpulkan terdapat hubungan yang positif dan signifikan antara tingkat pendidikan dengan persepsi masyarakat terhadap aktivitas penambangan galian C. Hal ini menunjukkan bahwa ada hubungan yang tinggi antara penddikan dengan persepsi masyarakat.Hal ini berarti bahwa semakin tinggi pendidikan maka persepsi akan aktivitas penambangan akan semakin positif.

Sejalan dengan penelitian yang dilakukan Nurkaromah (2017), menjelaskan bahwa semakin tinggi pendidikan yang ditempuh, semakin banyak pula proses pengembangan dan pengarahan yang dilalui dan didapatkan seseorang yang dapat mempengaruhi persepsi, hal tersebut juga sebaliknya apabila semakin rendah tingkat pendidikan maka semakin buruk persepsinya.

2. Hubungan Tingkat Pendapatan Dengan

Persepsi Masyarakat Terhadap Aktivitas

Penambangan Galian C

Hasil uji statistik (Uji Kendall Tau) sebagaiman diuraikan pada tabel 6 diketahui nilai Sig.(2-tailed) sebesar 0,633 dan nilai Correlation Coefficient negatif 0,043. Nilai Sig 0,633 >0,050, sehingga dapat disimpulkan hubungan antara tingkat pendapatan dengan persepsi masyarakat terhadap aktivitas penambangan galian $\mathrm{C}$ cenderung negatif dan tidak signifikan. Hal ini disebabkan karena penghasilan yang didapat masyarakat bervariasi, selain disebabkan karena perbedaan pekerjaan, juga dapat disebabkan tingkat pendidikan 
yang berbeda-beda. Berdasarkan hasil olahan data primer diketahui tingkat pendapatan masyarakat C $(54,41 \%)$ termasuk dalam kategori rendah.

Hal ini tidak sejalan dengan hasil penelitian Alpian (2009), menyatakan bahwa masyarakat yang mempunyai pendapatan tinggi cenderung mempunyai tingkat persepsi positif, masyarakat yang mempunyai pendapatan sedang cenderung mempunyai tingkat persepsi netral, sedangkan masyarakat yang mempunyai pendapatan rendah cenderung mempunyai tingkat persepsi negatif.

3. Hubungan Persepsi Masyarakat Terhadap Aktivitas Penambangan Galian C Dengan Tingkat Kosmopolitan

Hasil uji statistik (Uji Kendall Tau) sebagaiman diuraikan pada tabel 6 diketahui nilai Sig.(2-tailed) sebesar 0,352 dan nilai Correlation Coefficient negatif sebesar 0,090. Nilai Sig 0,352>0,050, sehingga dapat disimpulkan bahwa terdapat hubungan yang negatif dan tidak signifikan antara tingkat kosmopolitan dengan persepsi masyarakat terhadap aktivitas penambangan galian C. Hal ini menunjukan bahwa tingkat kosmopolitan tidak mempengaruhi persepsi masyarakat terhadap aktivitas penambangan galian C di Desa Peniraman, (Ho diterima dan Ha ditolak). Artinya semakin tinggi tingkat kosmopolitan maka persepsi cenderung positif. Berdasarkan hasil pengamatan diketahui bahwa tingkat kosmopolitan masyarakat terhadap aktivitas penambangan galian $\mathrm{C}$ sebagian besar $(45,59 \%)$ cenderung sedang. Penelitian yang dilakukan Asang (2016), mengemukakan Perbedaan tingkat kosmopolitan terjadi karena adanya perbedaan sumber informasi yang diterima masyarakat. Kelompok masyarakat yang memiliki kosmopolitan tinggi dan sedang ialah masyarakat yang memiliki interaksi dengan dunia luar lebih banyak, baik interaksi dua arah maupun satu arah.

\section{Kesimpulan}

1. Persepsi masyarakat Desa Peniraman terhadap aktivitas penambangan galian $\mathrm{C}$ di Bukit Peniraman Desa Peniraman cenderung Positif

2. Terdapat hubungan yang positif dan signifikan antara tingkat pendidikan dengan persepsi masyarakat terhadap aktivitas penambangan galian $\mathrm{C}$ di Bukit Peniraman, Terdapat hubungan yang negatif dan tidak signifikan antara tingkat pendapatan dengan persepsi masyarakat terhadap aktivitas penambangan galian $\mathrm{C}$ di Bukit Peniraman, Terdapat hubungan yang negatif dan tidak signifikan antara tingkat kosmopolitan dengan persepsi masyarakat terhadap aktivitas penambangan galian $\mathrm{C}$ di Bukit Peniraman. Hal ini terjadi karena adannya kepentingan kebutuhan ekonomi dan lingkungan, sehingga tingkat pendapatan, tingkat kosmopolitan tidak memiliki hubungan yang nyata dengan persepsi masyarakat Desa Peniraman terhadap aktivitas penambangan Galian C.

\section{Saran}

1. Adanya persepsi yang positif dari masyarakat Desa Peniraman terhadap aktivitas penambangan Galian C di Bukit Peniraman, maka pemerintah daerah bersama pihak perusahaan dapat memotivasi masyarakat dalam upaya 
menjaga lingkungan, salah satunya dengan cara setelah dilakukannya penggerusan, sebaiknya dilakukan reboisasi atau penghijauan kembali agar dapat mempertahankan fungsi ekosistem hutan dan meningkatkan perekonomian masyarakat setempat untuk kebutuhan hidupnya.

2. Perlu ditingkatkan kesadaran masyarakat terkait pentingnya menjaga kelestarian hutan melalui kegiatan penyuluhan dari dinas terkait, serta perlunya meningkatkan kerjasama masyarakat dalam meningkatkan kualitas dari hutan yang ada di Bukit Peniraman, Desa Peniraman, Kecamatan Sungai Pinyuh, Kabupaten Mempawah.

\section{Ucapan terima kasih}

Penulis mengucapkan terimakasih kepada masyarakat Desa Peniraman Kecamatan Sungai Pinyuh Kabupaten Mempawah yang telah mengizinkan melakukan penelitian di desa tersebut dan telah memberikan respon yang sangat baik serta bersedia memberikan informasi dan ilmu yang berkaitan dengan penelitian sehingga penelitian ini berjalan dengan lancar tanpa suatu kendala apapun.

\section{DAFTAR PUSTAKA}

Alpian S. 2009. Persepsi masyarakat terhadap ketentuan larangan berburu satwa liar dalam dan sekitar taman nasional danau sentarum kabupaten kapuas hulu [Skripsi]. Jurnal hutan lestari.

Asang, Lumangkun A, Wardenaar E. 2016. Persepsi masyarakat terhadap rencana penetapan kawasan riam sengiang sebagai objek wisata alam di Desa nanga kempangai kabupaten melawi. Jurnal Hutan Lestari. 4(4): 427-436.
Dela Vj. 2015. Persepsi Masyarakat Perkotaan Terhadap Pentingnya Fungsi Ruang Terbuka Hijau (Rth) Di Kota Pontianak. Jurnal Hutan Lestari. 4(3): 263-272.

Desmita. 2016. Psikologi Perkembangan Peserta Didik Cet ke 6. Bandung. PT Remaja Rosda Karya.

Hasril H. 1980. Dasar-Dasar Teori Penggunaan Teknik Pengambilan Contoh (Sampling Techniques) Dalam Inventarisasi Hutan. Jakarta. Pradnya paramita.

Jamaril, Saiful U, dan Amirullah. 2016. Persepsi Masyarakat Terhadap Dampak Penambangan Batu Akik (Studi di Kecamatan Panga Kabupaten Aceh Jaya). Jurnal Ilmiah Mahasiswa Pendidikan Kewarganegaraan Unsyiah. 1(1): 8088.

Khadapi H. 2015. Persepsi Masyarakat Desa Sungai Awan Kanan Terhadap Keberadaan

Hutan Mangrove Di Kawasan Pantai Air Mata Permai Kabupaten Ketapang. Jurnal

Hutan Lestari. 1(4): 108-116.

Muin S. 2018. Penilain Potensi Daya Tarik dan Permintaan Ekowisata Mempawah Mangrove Park Desa Pasir Kabupaten Mempawah Kalimantan Barat. Laporan Penelitian PNDP (DIPA) Fakultas Kehutanan Untan. Tahun 2018. Tidak Dipublikasikan.

Ni'am AL, Mussadun. 2014. Dampak Aktivitas Ekowisata Di Pulau Karimunjawa Berdasarkan Persepsi Masyarakat. Jurnal Teknik PWK(Perencanaan Wilayah Kota). 3(2): 262-273. 
Nurkaromah K, Yanzi H, Pitoewas B. 2017. Hubungan Tingkat Pendidikan Dengan Persepsi Orang Tua Terhadap Lulusan Perguruan Tinggi Di Desa Gadingrejo Utara Kecamatan Gadingrejo Kabupaten Pringsewu. Jurusan Pendidikan Ilmu Pengetahuan Sosial. 5(2): 2017.

Priyatno D. 2010. Belajar Cepat Oleh Data Statistik Dengan Spss. Yogyakarta. Mediakom.

Sugiyono. 2017. Metode Penelitian Kuantitatif, Kualitatif, dan $R \& D$.Bandung. Alfabeta.

Slameto. 2013. Belajar dan Faktor-faktor Yang Mempengaruhi. Cet 6. Jakarta. Rineka Cipta.
Surati. (2014). Analisis sikap dan perilaku masyarakat terhadap Hutan Penelitian Parung Panjang. Jurnal Penelitian Sosial dan Ekonomi Kehutanan. 11(4): 339-347.

Sunyoto D, Burhanudin. 2011. Perilaku Organisasional Cet ke 1. Yogyakarta. CAPS.

Rahmawati D. 2011. Pengaruh Kemiskinan Terhadap Maraknya Pertambangan Tanpa Ijin. Jurnal Media Bina Ilmiah. 5(8): 1978-3787. Fakultas Teknik. Universitas Muhammadiyah Mataram. Lombok Barat. 